\title{
Communication
}

\section{Unusual Nondispersive Ambipolar Carrier Transport and High Electron Mobility in Amorphous Ter(9,9-diarylfluorene)s}

Chung-chih Wu, Tsung-Li Liu, Wen-Yi Hung, Yu-Ting Lin, Ken-Tsung

Wong, Ruei-Tang Chen, You-Ming Chen, and Yuh-Yih Chien

J. Am. Chem. Soc., 2003, 125 (13), 3710-3711• DOI: 10.1021/ja029630m • Publication Date (Web): 07 March 2003

\section{Downloaded from http://pubs.acs.org on February 17, 2009}

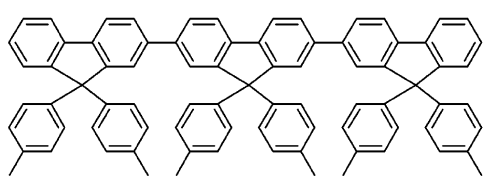

1

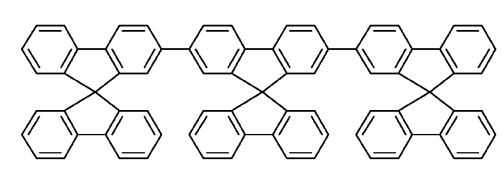

2

\section{More About This Article}

Additional resources and features associated with this article are available within the HTML version:

- $\quad$ Supporting Information

- $\quad$ Links to the 27 articles that cite this article, as of the time of this article download

- Access to high resolution figures

- $\quad$ Links to articles and content related to this article

- $\quad$ Copyright permission to reproduce figures and/or text from this article

\section{View the Full Text HTML}




\title{
Unusual Nondispersive Ambipolar Carrier Transport and High Electron Mobility in Amorphous Ter(9,9-diarylfluorene)s
}

\author{
Chung-chih Wu, ${ }^{*}, \dagger$ Tsung-Li Liu, ${ }^{\dagger}$ Wen-Yi Hung, ${ }^{\dagger}$ Yu-Ting Lin, ${ }^{\dagger}$ Ken-Tsung Wong,,${ }^{*} \neq$ \\ Ruei-Tang Chen, ${ }^{\ddagger}$ You-Ming Chen, ${ }^{\ddagger}$ and Yuh-Yih Chien ${ }^{\ddagger}$ \\ Department of Electrical Engineering, Graduate Institute of Electrooptical Engineering, Graduate Institute of \\ Electronics Engineering, and Department of Chemistry, National Taiwan University, Taipei 106, Taiwan
}

Received December 7, 2002; E-mail: chungwu@cc.ee.ntu.edu.tw

Advances in organic electronics and optoelectronics in recent years have imposed substantial demands in amorphous molecular charge transport materials with morphological stability. ${ }^{1}$ While amorphous hole-transport materials with nondispersive carrier transport and mobility around $10^{-3} \mathrm{~cm}^{2} /(\mathrm{V} \cdot \mathrm{s})$ abound, electrontransport materials in general are rare, often suffer from dispersive transport due to carrier trapping, and usually possess electron mobility orders of magnitude lower than the best mobility of holetransport materials. ${ }^{1}$ Further, although bipolar transport materials would be ideal for many applications, most of the existing charge transport materials show only unipolar transport in amorphous states. ${ }^{1}$ In this communication, we report the intriguing carriertransport properties of amorphous ter(9,9-diarylfluorene)s, in which unusual nondispersive ambipolar carrier transport and high electron mobility in excess of $10^{-3} \mathrm{~cm}^{2} /(\mathrm{V} \cdot \mathrm{s})$ were observed for the first time for amorphous molecular semiconductors containing only a single type of chromophore.

Ter(9,9-diarylfluorene)s $\mathbf{1}$ and $\mathbf{2}$ under investigation are shown in Figure 1. Our previous studies have revealed some of their intriguing and promising characteristics, such as the steric and helical conformation of the peripheral aryl subsituents and the fluorene moieties along the backbone, high glass transition temperatures of $>200{ }^{\circ} \mathrm{C}$, high thin-film photoluminescence (PL) quantum yields of $90 \%$ in pure blue, and electrochemical stability as indicated by both reversible oxidation and reduction. ${ }^{2}$ They form homogeneous films with vacuum deposition, and the amorphous nature of films was confirmed by powder X-ray diffraction. These compounds had been applied in blue light-emitting devices as the emitting layer, exhibiting promising device characteristics and suggesting their carrier-transport capability. ${ }^{2}$

Charge transport in films was typically characterized in a vacuum by applying the time-of-flight (TOF) transient photocurrent technique on glass/Ag $(30 \mathrm{~nm}) /$ organic $(1.5 \mu \mathrm{m}) / \mathrm{Al}(150 \mathrm{~nm})$ samples. $^{1 \mathrm{c}}$ Pulsed illumination (third harmonic of Nd:YAG laser, $355 \mathrm{~nm}, 10$ $\mathrm{ns})$ through the semitransparent electrode $(\mathrm{Ag})$ induces photogeneration of a thin sheet of excess carriers. The sample thickness had been chosen to be much larger than the optical absorption depth of the excitation. Depending on the polarity of the applied bias, selected photogenerated carriers (holes or electrons) are swept across the sample with a transit time $T_{\mathrm{t}}$. With the applied bias $V$ and the sample thickness $D$, the applied electric field $E$ is then $V / D$, and the carrier mobility is given by $\mu=D /\left(T_{\mathrm{t}} \cdot E\right)=D^{2} /\left(V \cdot T_{\mathrm{t}}\right)$.

These amorphous terfluorenes exhibit ambipolar carrier transport and high mobilities for both carriers. Figure $2 \mathrm{a}-\mathrm{d}$ shows representative TOF transients of electrons and holes for $\mathbf{1}$ and $\mathbf{2}$ measured in a vacuum at room temperature. In all cases, the short initial spike, limited by the time resolution of the measurement setup, is followed

\footnotetext{
Department of Electrical Engineering.

¥Department of Chemistry.
}
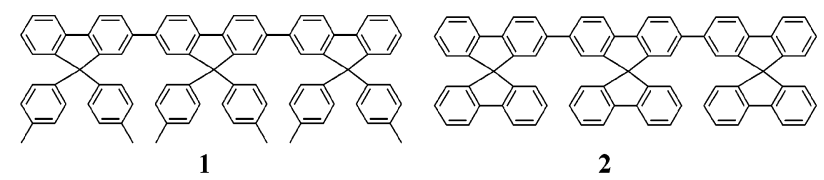

Figure 1. Chemical structures of ter(9,9-diarylfluorene)s: 1 and 2.
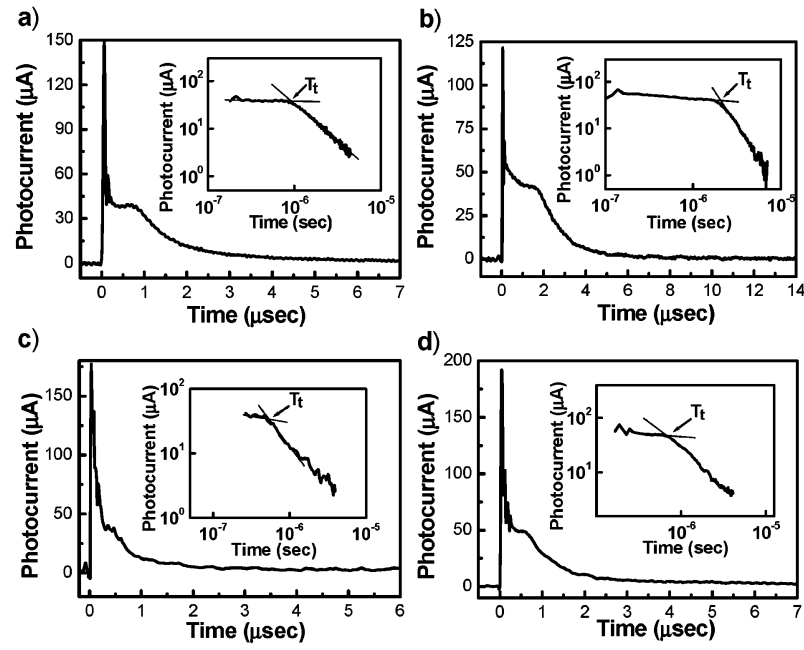

Figure 2. Representative TOF transients for $\mathbf{1}$ and $\mathbf{2}$ samples (both 1.5 $\mu \mathrm{m}$ thick): (a) $\mathbf{1}$, electron, $E=3.3 \times 10^{5} \mathrm{~V} / \mathrm{cm}$, (b) $\mathbf{1}$, hole, $E=3.3 \times 10^{5}$ $\mathrm{V} / \mathrm{cm}$, (c) 2 , electron, $E=6.7 \times 10^{5} \mathrm{~V} / \mathrm{cm}$, (d) 2 , hole, $E=8 \times 10^{4} \mathrm{~V} / \mathrm{cm}$. Insets of $(a-d)$ are double logarithmic plots of $(a-d)$.

first by a clear constant-current plateau and then by a drop. The observation of a plateau indicates that the charge carriers have attained a constant drift velocity and hence nondispersive transport. ${ }^{1 \mathrm{c}}$ In the double logarithmic representation (inset of Figure 2), the carrier transit time, $T_{\mathrm{t}}$, can be unambiguously evaluated from the intersection point of the asymptotes to the plateau and the tail sections. The carrier mobilities thus determined for $\mathbf{1}$ and $\mathbf{2}$ versus $E^{1 / 2}$ are shown in Figure 3. These terfluorenes retain characteristics of nondispersive ambipolar carrier transport and high mobilities in air. For instance, Figure 3 also shows the mobilities of $\mathbf{1}$ measured in air after extended ( $24 \mathrm{~h}$ ) exposure to ambient, which exhibit only a slight lowering from those obtained in a vacuum, indicating relative environmental stability of the carrier-transport properties. The field-dependence of mobilities in Figure 3 follows the nearly universal Poole-Frenkel relationship: $\mu \propto \exp \left(\beta E^{1 / 2}\right)$, where $\beta$ is the Poole-Frenkel factor. ${ }^{3-5}$ Such a relationship had been previously observed in various disordered organic systems and could be attributed to the effects of energetic and positional disorder on the hopping conduction in amorphous molecular solids. ${ }^{1 \mathrm{c}, 3-5}$

The electron mobilities observed here are unusually high. In particular, the electron mobility of over $10^{-3} \mathrm{~cm}^{2} /(\mathrm{V} \cdot \mathrm{s})$ for $\mathbf{1}$ is 


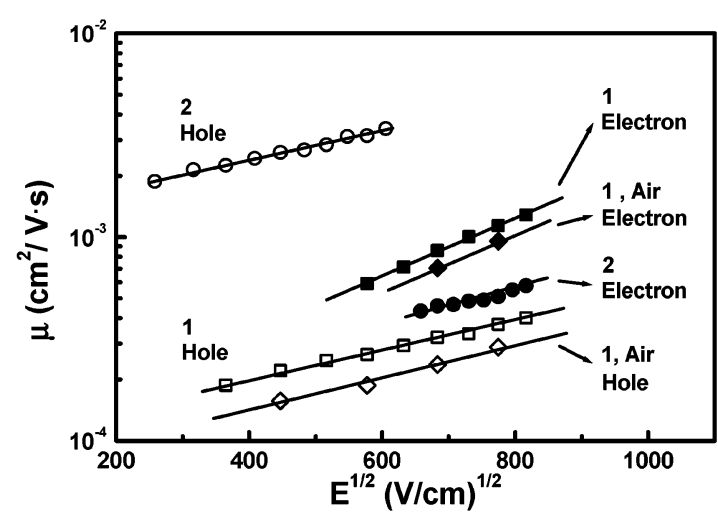

Figure 3. Electron and hole mobilities versus $E^{1 / 2}$ for $\mathbf{1}$ and $\mathbf{2}$.

about 1 order higher than the highest previously reported value in amorphous molecular solids. ${ }^{1,5}$ Electron transport in disordered molecular solids occurs via hopping, which can be viewed as a one-electron reduction process of a neutral molecule concomitant with the oxidation of its anion. Thus, it is usually believed that for electron-transport materials, large solid-state electron affinity (EA) is essential to form stable anions in organic solids and to reduce trapping due to oxygen. ${ }^{1}$ Many reported electron-transport materials thereby have attachment of strong electron-withdrawing groups to or introduction of electron-accepting heterocyclic rings to extended $\pi$-electron conjugated systems for achieving large EA. ${ }^{5}$ The present work, however, clearly shows that purely phenyl-based conjugated systems can achieve superior electron transport and environmental stability.

Fluorene-based polymers or compounds have attracted wide interest in recent years as efficient blue emitters. ${ }^{2,6,7}$ It is noteworthy that, although there were few reports on the hole transport of fluorene-based materials, ${ }^{7}$ this is the first report of nondispersive electron and ambipolar transport in fluorene-based materials. Although thorough understanding requires further studies, several factors may contribute in distinguishing the present ter(9,9diarylfluorene)s from previous works. First, the well-defined conjugation length in the oligomeric systems may prevent formation of deep electron traps due to structural defects that could possibly occur in polymeric systems. Second, the types of substituents on C9 seem to subtly affect the carrier transport, as manifested by the significant difference in transport properties of $\mathbf{1}$ and $\mathbf{2}$. We notice that all of the other reports were based on alkyl substituents on C9, in contrast with rigid and bulky aryl substituents here. The aryl substituents provide intrinsically stronger $\mathrm{Csp}^{3}-\mathrm{Csp}^{2}$ bonding to $\mathrm{C} 9$ and could affect the molecular packing and morphology in films. Both may contribute in preventing the formation of deep electron traps.

Hole mobilities of the present terfluorenes are also high. In particular, the hole mobility up to $4 \times 10^{-3} \mathrm{~cm}^{2} /(\mathrm{V} \cdot \mathrm{s})$ for 2 is comparable to the best of the currently dominant arylamine-based materials. ${ }^{1,4}$ Together with superior electron transport, these ter(9,9-diarylfluorene)s exhibit unprecedented nondispersive ambipolar transport with comparably high electron and hole mobilities for amorphous molecular solids that contain only a single type of chromophores. Nondispersive ambipolar transport in condensed molecular systems composed of a single type of chromophores was observed previously only in somewhat ordered systems, such as in crystalline or liquid crystalline states. ${ }^{8}$ In amorphous systems, although bipolar transport was observed in few cases using the mixture of hole-transport and electron-transport chromophores or using "bipolar" molecules containing chemically connected holetransport and electron-transport chromophores, ${ }^{1 \mathrm{a}, 3 \mathrm{c}, 5 \mathrm{~b}, \mathrm{c}}$ both electrons and holes usually suffered from degraded transport mobilities, presumably due to the dilution effect or complication of interchromophore interactions.

In summary, the intriguing carrier-transport properties of ter(9,9-diarylfluorene)s are reported. The findings here in many aspects are contrary to previous observations. Further understanding of these unusual carrier-transport phenomena is currently under pursuit, to shed more light on the nature and design of organic charge transport materials.

Acknowledgment. Financial support from the National Science Council and Ministry of Education of Taiwan is acknowledged.

Supporting Information Available: Experimental details of sample preparation and measurements (PDF). This material is available free of charge via the Internet at http://pubs.acs.org.

\section{References}

(1) (a) Strohriegl, P. Adv. Mater. 2002, 14, 1439 and references therein. (b) Shirota, Y. J. Mater. Chem. 2000, 10, 1. (c) Borsenberger, P. M.; Weiss, D. S. Organic Photoreceptors for Imaging Systems; Marcel Dekker: New York, 1993 and references therein.

(2) Wong, K.-T.; Chien, Y.-Y.; Chen, R.-T.; Wang, C.-F.; Lin, Y.-T.; Chiang, H.-H.; Hsieh, P.-Y.; Wu, C.-C.; Chou, C. H.; Su, Y. O.; Lee, G.-H.; Peng, S.-M. J. Am. Chem. Soc. 2002, 124, 11576.

(3) (a) Bässler, H. Philos. Mag. B 1992, 65, 795. (b) Bässler, H. Phys. Status Solidi B 1993, 15, 175. (c) Bässler, H. Int. J. Mod. Phys. 1994, 8, 847. (d) Gill, W. D. J. Appl. Phys. 1972, 43, 5033.

(4) (a) Borsenberger, P. M.; Pautmeier, L.; Richert, R.; Bässler, H. J. Chem. Phys. 1991, 94, 8276. (b) Okumoto, K.; Shirota, Y. Mater. Sci. Eng. 2001, B85, 135 .

(5) (a) Borsenberger, P. M.; Detty, M. R.; Magin, E. H. Phys. Status Solidi B 1994, 185, 465. (b) Tokuhisa, H.; Era, M.; Tsutsui, T.; Saito, S. Appl. Phys. Lett. 1995, 66, 3433. (c) Lin, L.-B.; Jenekhe, S. A.; Borsenberger, P. M. Appl. Phys. Lett. 1996, 69, 3495. (d) Bettenhausen, J.; Strohriegl, P.; Brütting, W.; Tokuhisa, H.; Tsutsui, T. J. Appl. Phys. 1997, 82, 49574961. (e) Redecker, M.; Bradley, D. D. C.; Jandke, M.; Strohriegl, P. Appl. Phys. Lett. 1999, 75, 109. (f) Naka, S.; Okada, H.; Onnagawa, H.; Tsutsui, T. Appl. Phys. Lett. 2000, 76, 197. (g) Malliaras, G. G.; Shen, Y.; Dunlap, D. H.; Murata, H.; Kafafi, Z. H. Appl. Phys. Lett. 2001, 79 2582. (h) Murata, H.; Malliaras, G. G.; Uchida, M.; Shen, Y.; Kafafi, Z H. Chem. Phys. Lett. 2001, 339, 161. (i) Tamao, K.; Uchida, M.; Izumizawa, T.; Furukawa, K.; Yamaguchi, S. J. Am. Chem. Soc. 1996, 118, 11974. (j) Sakamoto, Y.; Suzuki, T.; Miura, A.; Fujikawa, H.; Tokito S.; Taga, Y. J. Am. Chem. Soc. 2000, 122, 1832.

(6) (a) Katsis, D.; Geng, Y. H.; Ou, J. J.; Culligan, S. W.; Trajkovska, A. Chen, S. H.; Rothberg, L. J. Chem. Mater. 2002, 14, 1332. (b) Geng, Y.; Katsis, D.; Culligan, S. W.; Ou, J. J.; Chen, S. H.; Rothberg, L. J. Chem. Mater. 2002, 14, 463. (c) Belletête, M.; Ranger, M.; Beaupré, S.; Leclerc, M.; Durocher, G. Chem. Phys. Lett. 2000, 316, 101. (d) Beaupré, S.; Ranger, M.; Leclerc, M. Macromol. Rapid Commun. 2000, 21, 1013. (e) Setayesh, S.; Grimsdale, A. C.; Weil, T.; Enkelmann, V.; Müllen, K.; Meghdadi, F.; List, E. J. W.; Leising, G. J. Am. Chem. Soc. 2001, 123, 946. (f) Weinfurtner, K.-H.; Weissortel, F.; Harmgarth, G.; Salbeck, J. Proc. SPIE-Int. Soc. Opt. Eng. 1998, 3476, 40.

(7) (a) Markham, J. P. J.; Anthopoulos, T. D.; Samuel, I. D. W.; Richards, G. J.; Burn, P. L.; Im, C.; Bässler, H. Appl. Phys. Lett. 2002, 81, 3266. (b) Redecker, M.; Bradley, D. D. C.; Inbasekaran, M.; Woo, E. P. Appl. Phys. Lett. 1998, 73, 1565. (c) Redecker, M.; Bradley, D. D. C. Inbasekaran, M.; Woo, E. P. Appl. Phys. Lett. 1999, 74, 1400. (d) Campbell, A. J.; Bradley, D. D. C.; Antoniadis, H. Appl. Phys. Lett. 2001 79, 2133. (e) Redecker, M.; Bradley, D. D. C.; Inbasekaran, M.; Wu, W. W.; Woo, E. P. Adv. Mater. 1999, 11, 241.

(8) (a) Schein, L. B. Phys. Rev. 1977, B15, 1024 and references therein. (b) Funahashi, M.; Hanna, J.-I. Appl. Phys. Lett. 1998, 73, 3733. (c) Méry, S.; Haristoy, D.; Nicoud, J.-F.; Guillon, D.; Diele, S.; Monobe, H.; Shimizu, Y. J. Mater. Chem. 2002, 12, 37-41 and references therein.

JA029630M 